\title{
Cell receptors for influenza $A$ viruses and the innate immune response
}

\author{
Irene Ramos ${ }^{1}$ and Ana Fernandez-Sesma ${ }^{1,2}$ * \\ 1 Department of Microbiology, Mount Sinai School of Medicine, New York, NY, USA \\ ${ }^{2}$ Global Health and Emerging Pathogens Institute, Mount Sinai School of Medicine, New York, NY, USA
}

\section{Edited by:}

Yasuko Yokota, National Institute of Infectious Diseases, Japan

\section{Reviewed by:}

Hideki Hasegawa, National Institute of Infectious Diseases, Japan

Cornelis Alexander De Haan, Utrecht University, Netherlands

*Correspondence:

Ana Fernandez-Sesma, Department of Microbiology, Mount Sinai School of Medicine, One Gustave L. Levy Place, Box 1124, New York, NY 10029, USA.

e-mail:ana.sesma@mssm.edu
The interaction of the hemagglutinin (HA) of the influenza A viruses (IAV) with the cell surface is a key factor for entry of the virus and productive infection of the cell. This glycoprotein has affinity for sialic acids (SA), and different strains present specificity for SA bound through $\alpha 2,3$ or $\alpha 2,6$ linkages to the underlying sugar chain, which is usually related with host and cell tropism. Nucleic acid recognizing receptors (mainly RIG-I and Toll-like receptors) are the most extensively studied pattern recognition receptors for IAV. However, due to the ability of the HA of avian, swine, or human influenza viruses to bind differently linked SA and also to the high levels and variability of glycosylations of their major virion glycoprotein components, HA and NA, IAV interacting proteins on the cell surface could also play an important role in initiating different signaling pathways to elicit the immune response in infected cells. But, at present, these processes are not well understood. In this mini-review we discuss how the interactions of IAV with cell surface receptors on immune cells might be important for the induction of specific innate immune responses and as a result, for pathogenicity in humans.

Keywords: influenza virus, receptors, sialic acids, innate immune response

\section{INTRODUCTION}

Influenza viruses are an important threat to human health and global economy, causing an annual average of 36,000 deaths and over 200,000 hospitalizations during the 1990s (CDC, 2010). In addition, due to the high frequency of mutations and recombination of their genome (antigenic drift and shift), and their airborne transmission, they have a high potential to become pandemic viruses. Influenza viruses belong to the family Orthomyxoviridae, and include the types, A, B, and C, from which influenza A viruses (IAV) are the responsible for most of the disease burden (Mubareka and Palese, 2011). IAV have a segmented negative stranded RNA genome, consisting on 8 segments that encode up to 12 proteins (Palese and Shaw, 2007; Wise et al., 2009).

The major glycoproteins present on the surface of the virion are the hemagglutinin (HA) and the neuraminidase (NA). To date, $16 \mathrm{HA}$ and 9 NA subtypes have been described, and the combination of different subtypes of these proteins results in different subtypes of IAV (Mubareka and Palese, 2011). The main roles of the HA are to mediate the interaction of the viral particle with the cell components on the surface and to promote the fusion of the viral and endosomal membranes, leading to the release of the

Abbreviations: CLRs, C-type lectin receptors; DCs, dendritic cells; DC-SIGN, dendritic cell-specific intercellular adhesion molecule-3-grabbing non-integrin; EGFR, epidermal growth factor receptor; HA, hemagglutinin; HPAIV, high pathogenic influenza avian viruses; IAV, influenza A virus; NA, neuraminidase; NLRs, Nod-like receptors; PI3K, phosphatidylinositol 3-kinases; PRRs, pattern recognition receptors; RLRs, RIG-I-like receptors; RNP, ribonucleoprotein; RTK, receptor tyrosine kinases; SA, sialic acids; TLRs, Toll-like receptors. ribonucleoproteins (RNP) into the cytoplasm. The interaction of influenza viruses with their receptors is necessary for subsequent internalization of the virus. Some studies demonstrated that IAV enter the cell via clathrin mediated endocytosis, although under certain conditions they can also enter in a caveolin and clathrin independent manner (Lakadamyali et al., 2004, 2006; De Vries et al., 2011).

Here we review and discuss how the interaction of IAV with their receptors on the cell surface of immune cells, such as dendritic cells (DCs) and macrophages, might influence infection and promote specific innate immune responses, with important implications in the outcome of the disease, either promoting viral clearance or generating exacerbated local immune responses resulting in acute infection and increased pathogenesis.

\section{RECEPTOR SPECIFICITY OF THE IAV}

The circulation of IAV is species-specific, and therefore, transmission among different species is usually not observed. It is known that the receptor specificity has an important role in maintaining the host species barrier, although other proteins, like PB2, also need to be adapted for efficient infection of other hosts different than the original host (Almond, 1977; Neumann and Kawaoka, 2006). Sialic acids (SA, $N$-acetylneuraminic acid) are the primary receptors for virus attachment to cell surfaces, binding to a pocket at the distal tip of the HA of IAV (Weis et al., 1988). SA consist of nine carbon sugars frequently attached through $\alpha 2,3$ or $\alpha 2,6$ (SA $\alpha 2,3$ or $S A \alpha 2,6)$ linkages to underlying sugar chains of glycoproteins in the cell membrane. It is known that avian and human viruses differ in their SA binding affinity, since HA from human isolates usually bind $S A \alpha 2,6$, while the avian isolates usually have affinity 
for SA 2 2,3 (Rogers and Paulson, 1983). Related to this, human upper respiratory tract present mainly $S A \alpha 2,6$, which is believed to act as one of the main barriers for transmission of avian IAV to humans (Shinya et al., 2006; Van Riel et al., 2006; Nicholls et al., 2007).

High pathogenic avian influenza viruses (HPAIV) $\mathrm{H} 5 \mathrm{~N} 1$ are currently a pandemic threat, and almost 600 people have been reported to be infected as of November 15, 2011 (WHO, 2011), resulting in severe pneumonia with a lethal outcome in $60 \%$ of those reported cases. Humans infected with $\mathrm{H} 5 \mathrm{~N} 1$ present unusually high serum concentrations of chemokines and proinflammatory cytokines, which are thought to contribute to disease severity (Peiris et al., 2004; De Jong et al., 2006; Maines et al., 2008; Sirinonthanawech et al., 2011). Although no sustained human-to-human transmission has been established yet, possibly due to the low levels of SA $\alpha 2,3$ present in the human airways, HPAIV have been shown to be able to infect and replicate efficiently in cells in the lower region of the respiratory tract, including type II pneumocytes and alveolar macrophages, where the avian-like virus receptor is predominant (Shinya et al., 2006; Van Riel et al., 2006; Nicholls et al., 2007). Therefore, the receptor specificity of influenza viruses is important not only for the host tropism, but also for tissue tropism in humans, since it determines the airway region and cell types that support active viral replication, what might contribute to the severity of the disease observed in humans infected with HPAIV. Moreover, a recent work by Watanabe et al. (2011) showed that a single aminoacid change in the HA (D222G) of a H1N1 2009 pandemic $\mathrm{IAV}$, which is determinant for the receptor binding preference modification from $\mathrm{SA} \alpha 2,6$ to mixed $\mathrm{SA} \alpha 2,3$ and $\mathrm{SA} \alpha 2,6$, correlated with severe infection in macaques and higher replication in human lung tissue. It is believed that modifications in the receptor specificity of avian $\mathrm{H} 5 \mathrm{~N} 1$ influenza virus would be necessary to allow human-to-human direct transmission (Enserink, 2007; Tumpey et al., 2007). However, some studies indicate that a change from $S A \alpha 2,3$ to $S A \alpha 2,6$ binding preference is not enough to increase transmission efficiency in ferrets (Maines et al., 2006; Chen et al., 2012), which are a suitable animal model for the study of influenza since they are susceptible to human influenza viruses (Matsuoka et al., 2009), suggesting that several molecular changes, not only in the HA gene but also in other segments, would be required to confer efficient fitness in humans and become pandemic.

The development of glycan arrays has provided highly valuable information regarding the receptor binding specificity of the HA of numerous IAV isolates (Stevens et al., 2006a,b). These assays allow researchers to determine the SA $\alpha 2,3$ or SA $\alpha 2,6$ glycans that interact with the viral HA or whole virus, by using a broad panel of synthetic polymers. Therefore, we now know that not only the $\mathrm{SA} \alpha 2,3$ or $\mathrm{SA} \alpha 2,6$ linkages, but also the underlying sugar chain features, like other modifications such as sulfation, fucosylations, or additional sialylation of the sialyl-receptors are determinant for the binding specificity of the HA, being very variable among the different IAV subtypes and isolates (Stevens et al., 2006a), which could be determinant not only in the host and cell tropism, but also in differential recognition by cell receptors.

\section{SIALYLATED GLYCANS AS RECEPTORS: INVOLVEMENT IN THE IMMUNE RESPONSE TO IAV AND PATHOGENESIS}

In the last few years, numerous studies have provided increasing evidence for a role for the viral HA-SA interaction in the induction of innate immunity and pathogenesis. SA are structural components of the cell surface, and they have important implications in the immune responses (Crocker and Varki, 2001; Videira et al., 2008). On the other hand, DCs are essential players in the induction of innate immunity, as well as in the initiation of adaptive responses. Upon sensing invading pathogens via several pattern recognition receptors (PRRs), they differentiate to mature DCs and migrate to the secondary lymphoid organs, where they present the processed antigen to T-lymphocytes. Importantly, human DCs express $S A \alpha 2,3$ and $S A \alpha 2,6$ on their surface (Videira et al., 2008; Ramos et al., 2011), and the levels of expression of sialyltransferases and therefore, the SA levels on the surface, are modulated during differentiation and maturation processes (Bax et al., 2007; Videira et al., 2008). Additionally, it has also been shown that the elimination of the SA from the surface using a sialidase induced the maturation and activation of human DCs (Crespo et al., 2009), and that endogenous neuraminidase activity is necessary for the immune response to bacterial infections (Amith et al., 2009; Stamatos et al., 2010). These last studies reinforce the idea of a role for SA in immunity, and also could have implications in the immune responses against IAV, as the IAV NA is one important component of viral particles. One of the first reports suggesting the importance of HA-SA interaction in eliciting innate immune responses was published by Miller and Anders (2003), who showed that inactivated IAV are able to induce type I IFN production in mouse spleen cells in a SA-dependent manner. Herein, it is important to mention that the induction of type I IFN in immune cells by inactivated viruses via TLR7 could also be dependent on HA-SA interaction, since a more efficient SA-dependent entry of inactivated viruses would result in an enhanced recognition of viral ssRNA by TLR7 in the endosomes (Diebold et al., 2004).

Several studies have been performed comparing cytokine responses between avian $\mathrm{H} 5 \mathrm{~N} 1$ viruses and human $\mathrm{H} 1 \mathrm{~N} 1$ in immune and epithelial cells, and most were able to demonstrate that the H5N1 IAV induced the strongest production of cytokines and chemokines, as compared to H1N1 IAV (Cheung et al., 2002; Chan et al., 2005; Lee et al., 2008, 2009; Cheng et al., 2010). However, the viral factors responsible for this effect were not clearly determined, due to high disparity in the viral segments among the strains compared, and it is likely that a combination of them (HA, NS1, PB1-F2...) could account for these differences. In order to elucidate if differences in receptor specificity of the IAV are important for this hyper-induction of pro-inflammatory cytokines, we recently reported that recombinant viruses bearing the HA and NA from a HPAIV H5N1, which differed only in two amino-acids that were shown to modify receptor specificity, induced different cytokine profiles in human DCs, macrophages, and primary bronchial-epithelial cells (Ramos et al., 2011). Using these viruses with identical genes with the exception of two amino-acids in the HA we could clearly analyze the contribution of this important factor to the immune responses in human immune cells. Specifically, the recombinant IAV with avian-type receptor specificity $(226 \mathrm{Q} / 228 \mathrm{G})$ induced higher levels of type I IFN, TNF- $\alpha$, IP-10, 
RANTES, and IL-6 than the one with increased human-type receptor specificity $(226 \mathrm{~L} / 228 \mathrm{~S})$, indicating that the differential binding of the IAV to their receptors in the cell surface could contribute for the hyper-cytokinemia observed in HPAIV patients. These data indicate that recognition of IAV by cell surface receptors in immune cells could occur differently depending on their binding preference, as proposed in the model shown in Figure $\mathbf{1}$. In this hypothetical model, IAV could be detected by separate unknown receptors differently sialylated (either $S A \alpha 2,3$ or $S A \alpha 2,6$; Figure 1A), or by a receptor expressing both $S A \alpha 2,3$ and $S A \alpha 2,6$ (Figure 1B). In these two cases, engagement of avian IAV to a putative receptor containing $S A \alpha 2,3$ would result in activation of signaling pathways leading to increased cytokine production and inflammation. However, human IAV detection would result in delayed induction of cytokines. At that stage of infection, IAV proteins involved in innate immune evasion (such as NS1 or PB1-F2) could antagonize innate immunity, resulting in lower expression of pro-inflammatory cytokines.

On the other hand, another study by a different group found that recombinant HA proteins from an $\mathrm{H} 5 \mathrm{~N} 1$ and a $2009 \mathrm{H} 1 \mathrm{~N} 1$ virus were able to induce DC activation of murine DCs in a MyD88/TLR4 dependent manner (Liu et al., 2010), indicating a possible role for this Toll-like receptor (TLR) in recognition of IAV HA. In this work, no clear differences were observed between $\mathrm{H} 5$ and $\mathrm{H} 1 \mathrm{HAs}$, but it is important to note that the cytokine profile induced in murine DCs could differ of that observed in human DCs, probably due to different sialylation patterns in those two systems.
Interestingly, Eierhoff et al. (2010) recently discovered that IAV interact with epidermal growth factor receptor (EGFR) in a SA-dependent manner. They clearly showed that IAV attachment to this receptor tyrosine kinase (RTK) family member promotes its activation, resulting in increased IAV uptake. Furthermore, they observed recruitment of the regulatory subunit p85 of PI3K to the EGFR in response to viral attachment, indicating activation of downstream signaling pathways, which are necessary for endocytosis triggering. These results are of great relevance, indicating that the interaction of the viral particles with the cell surface via RTK might have important impact not only in viral uptake, as the authors demonstrated, but its activation could play a role also in the innate immune response to $\mathrm{IAV}$, since it is known that the EGFR pathway is involved in the production of IL- 8 by respiratory epithelial cells, resulting in neutrophils recruitment in airway inflammatory diseases (Subauste and Proud, 2001; Nakanaga et al., 2007). Moreover, as EGFR activation was observed to be SA-dependent, further studies to elucidate if the same signaling pathways are trigged by viruses with different $S A \alpha 2,3$ or $S A \alpha 2,6$ receptor specificity would be of great interest.

\section{IAV INTERACTION WITH CELL SURFACE CARBOHYDRATE RECOGNIZING RECEPTORS AND THE INNATE IMMUNE RESPONSE}

Influenza A viruses are recognized by different PRRs in host cells, leading to the initiation of the innate immune response aimed to defeat the virus. The most extensively studied receptors for IAV

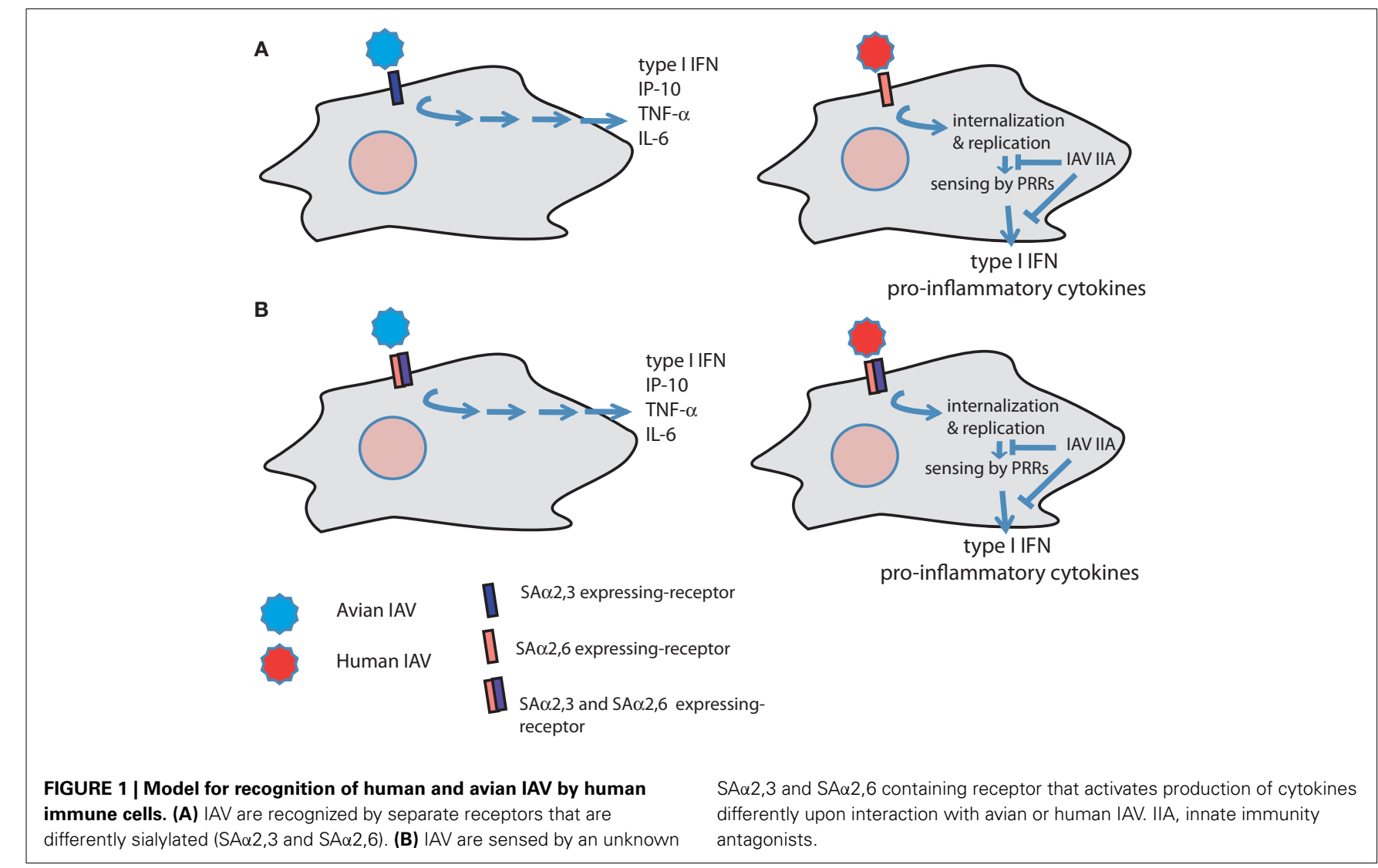


are nucleic acid recognizing receptors, such as RIG-I-like receptors (RLRs) and TLRs (Garcia-Sastre, 2011), and more recently, nucleotide oligomerization domain receptors or Nod-like receptors (NLRs) have been shown to have also an important role in IAV infection (Allen et al., 2009; Ichinohe et al., 2009). However, although not much attention has been paid so far to the IAV glycoproteins as pathogen associated molecular patterns (PAMPs) there is increasing evidence for the importance of their interaction with the host cell and the initiation of signaling pathways related with either internalization/endocytosis and cytokine production (Table 1).

Several studies showed that interactions of the HA of the IAV with C-type lectins receptors (CLRs) are important for IAV infectivity and for induction of type I IFN production in immune cells, since these are reduced upon pre-incubation with mannans and/or blocking antibodies (Miller and Anders, 2003; Londrigan et al., 2011; Seeds et al., 2011). CLRs are important PRRs in the immune response to pathogens, since they mediate attachment of the pathogens to DCs and macrophages. Attachment events facilitate phagocytosis, and also induce the activation of several signaling pathways that modulate immune responses to that pathogen (Geijtenbeek and Gringhuis, 2009).

Dendritic cell-specific intercellular adhesion molecule-3grabbing non-integrin (DC-SIGN) is one of the best-characterized CLRs, which is expressed in immature DCs and recognizes and binds to high mannose containing glycoproteins, commonly found in several pathogens, including viruses. $\mathrm{H} 5 \mathrm{~N} 1$ pseudotyped viruses were demonstrated to efficiently infect THP-1/DC-SIGN expressing cells, and the infectivity was reduced using DC-SIGN blocking antibodies (Wang et al., 2008). Another interesting observation in this manuscript was that DC-SIGN dependent entry was observed to be also dependent on SA. In contrast, another study focused in the role of DC-SIGN and L-SIGN in IAV entry, using SAdeficient cells and the virus strain BJx109 (H3N2), indicated that the entry mediated by these receptors was SA-independent (Londrigan et al., 2011). These discrepancies are likely to be due to differences on experimental designs as, for instance, the avian $\mathrm{H} 5$ and the $\mathrm{H} 3$ from $\mathrm{BJ} \times 109$ present affinity for differently galactoselinked SA (SA $\alpha 2,3$ and $\mathrm{SA} \alpha 2,6$, respectively). SIGN-R1 is one of the human DC-SIGN homologous proteins in mouse, and it is expressed in some subsets of macrophages and DCs in the spleen and the lymph node (Kang et al., 2003; Gonzalez et al., 2010; Lyszkiewicz et al., 2011). Similarly to human DC-SIGN, SIGN-R1 has also been reported to interact with IAV. Gonzalez et al. (2010) observed that a SIGN-R1-specific blocking antibody reduces IAV PR8 binding to lymph node DCs both in vitro and in vivo (using multiphoton intra-vital microscopy), and the viral uptake via this receptor was essential for local humoral immunity.

Additional C-type lectins that IAV have been shown to interact with are the murine macrophage galactose-type lectin (MGL) and macrophage mannose receptor (MMR). These interactions were observed to be SA-independent, and correlated with the different HA glycosylation levels of a few IAV strains (Reading et al., 2000; Upham et al., 2010). On the other hand, the mannose binding lectin (MBL), which is a soluble PRR belonging to the collectins family, is known to have anti-IAV activity, since it inhibits hemagglutination, resulting in viral neutralization, opsonizes viral particles allowing for better recognition and ingestion by phagocytic cells, and also activates the lectin complement pathway (Kawai et al., 2007; Chang et al., 2010; Gonzalez et al., 2010).

\section{CONCLUDING REMARKS}

The IAV interaction with surface cellular receptors is important for the pathogenesis and the immune responses generated in the host. The receptor specificity of IAV is determinant for allowing entry in the cell, and differential SA specificity accounts for host and cell tropism. Several specific cell receptors have been identified to interact with IAV in a SA-dependent or independent way. Further studies will allow for a better understanding of the outcome of these interactions and identification of new receptors, which could be important for the immune responses necessary for virus clearance or exaggerated responses that result in acute infections

Table 1 | Summary of cell surface or soluble host molecules reported to interact with IAV.

\begin{tabular}{|c|c|c|c|c|}
\hline $\begin{array}{l}\text { Cell receptor/ } \\
\text { interacting molecule }\end{array}$ & Host studied/cell types & IAV subtype & Remarks & Reference \\
\hline \multirow[t]{2}{*}{ DC-SIGN } & $\begin{array}{l}\text { B-THP-1, B-THP-1/DC-SIGN } \\
\text { (human), MDDCs (human) }\end{array}$ & H5N1 pseudotyped virus particles & SA-dependent interaction & Wang et al. (2008) \\
\hline & Lec2 CHO cells (hamster) & H3N2 and highly glycosylated H1N1 & SA-independent interaction & Londrigan et al. (2011) \\
\hline L-SIGN & Lec2 $\mathrm{CHO}$ cells & H3N2 and highly glycosylated H1N1 & SA-independent interaction & Londrigan et al. (2011) \\
\hline SIGN-R1 & Mouse model-in vivo/DCs & PR8 (H1N1) & Involved in humoral immunity & Gonzalez et al. (2010) \\
\hline MGL & J774E & H3N2, PR8 & SA-independent interaction & Upham et al. (2010) \\
\hline EGFR c-Met receptor & A549 (human) & H7N7 (avian), PR8 & SA-dependent interaction & Eierhoff et al. (2010) \\
\hline MBL (opsonization) & $\begin{array}{l}\text { Mouse model-in vivo/ } \\
\text { macrophages }\end{array}$ & PR8 (H1N1) & $\begin{array}{l}\text { Dispensable for humoral } \\
\text { immunity }\end{array}$ & Gonzalez et al. (2010) \\
\hline
\end{tabular}


and complications in high risk populations, as well as in infection by HPAIV. Recent data from several groups, including ours, strongly suggest that these receptors, when present in immune cells, might account for specific pro-inflammatory responses or facilitation of virus entry into cells. These findings may shed new light into the observed exacerbated immune responses in humans infected with viruses with different host tropism, such as HPAIV H5N1. Further studies need to be performed to analyze if IAV with different SA binding affinity indeed bind different receptors

\section{REFERENCES}

Allen, I. C., Scull, M. A., Moore, C. B., Holl, E. K., Mcelvania-Tekippe, E., Taxman, D. J., Guthrie, E. H., Pickles, R. J., and Ting, J. P. (2009). The NLRP3 inflammasome mediates in vivo innate immunity to influenza A virus through recognition of viral RNA. Immunity 30, 556-565.

Almond, J. W. (1977). A single gene determines the host range of influenza virus. Nature 270, 617-618.

Amith, S. R., Jayanth, P., Franchuk, S., Siddiqui, S., Seyrantepe, V., Gee, K., Basta, S., Beyaert, R., Pshezhetsky, A. V., and Szewczuk, M. R. (2009). Dependence of pathogen molecule-induced Toll-like receptor activation and cell function on Neu1 sialidase. Glycoconj. J. 26, 1197-1212.

Bax, M., Garcia-Vallejo, J. J., Jang-Lee, J., North, S. J., Gilmartin, T. J., Hernandez, G., Crocker, P. R., Leffler, H., Head, S. R., Haslam, S. M., Dell, A., and Van Kooyk, Y. (2007). Dendritic cell maturation results in pronounced changes in glycan expression affecting recognition by siglecs and galectins. J. Immunol. 179, 8216-8224.

CDC. (2010). Prevention and Control of Influenza with Vaccines. Recommendations of the Advisory Committee on Immunization Practices (ACIP). MMWR 59 (No. RR-8). Atlanta: Office of Surveillance, Epidemiology, and Laboratory Services, Centers for Disease Control and Prevention (CDC).

Chan, M. C., Cheung, C. Y., Chui, W. H., Tsao, S. W., Nicholls, J. M., Chan, Y. O., Chan, R. W., Long, H. T., Poon, L. L., Guan, Y., and Peiris, J. S. (2005). Proinflammatory cytokine responses induced by influenza A (H5N1) viruses in primary human alveolar and bronchial epithelial cells. Respir. Res. 6, 135.

Chang, W. C., White, M. R., Moyo, P., Mcclear, S., Thiel, S., Hartshorn, K. L., and Takahashi, K. (2010). Lack of the pattern recognition molecule mannose-binding lectin increases susceptibility to influenza A virus infection. BMC Immunol. 11, 64. doi:10.1186/1471-2172-11-64

Chen, L. M., Blixt, O., Stevens, J., Lipatov, A. S., Davis, C. T., Collins, B. E., Cox, N. J., Paulson, J. C., and Donis, R. O. (2012). In vitro evolution of $\mathrm{H} 5 \mathrm{~N} 1$ avian influenza virus toward human-type receptor specificity. Virology 422, 105-113.

Cheng, X., Xu, Q., Song, E., Yang, C. F., Kemble, G., and Jin, H. (2010). The hemagglutinin protein of influenza A/Vietnam/1203/2004 (H5N1) conflammatory cytokines in human epithelial cells. Virology 406, 28-36.

Cheung, C. Y., Poon, L. L., Lau, A. S., Luk, W., Lau, Y. L., Shortridge, K. F., Gordon, S., Guan, Y., and Peiris, J. S. (2002). Induction of proinflammatory cytokines in human macrophages by influenza $\mathrm{A}$ (H5N1) viruses: a mechanism for the unusual severity of human disease? Lancet 360, 1831-1837.

Crespo, H. J., Cabral, M. G., Teixeira, A. V., Lau, J. T., Trindade, H., and Videira, P. A. (2009). Effect of sialic acid loss on dendritic cell maturation. Immunology 128, e621-e631.

Crocker, P. R., and Varki, A. (2001). Siglecs, sialic acids and innate immunity. Trends Immunol. 22, 337-342.

De Jong, M. D., Simmons, C. P., Thanh, T. T., Hien, V. M., Smith, G. J., Chau, T. N., Hoang, D. M., Chau, N. V., Khanh, T. H., Dong, V. C., Qui, P. T., Cam, B. V., Ha Do, Q., Guan, Y., Peiris, J. S., Chinh, N. T., Hien, T. T., and Farrar, J. (2006). Fatal outcome of human influenza A (H5N1) is associated with high viral load and hypercytokinemia. Nat. Med. 12, 1203-1207.

De Vries, E., Tscherne, D. M., Wienholts, M. J., Cobos-Jimenez, V., Scholte, F., Garcia-Sastre, A., Rottier, P. J., and De Haan, C. A. (2011). Dissection of the influenza A virus endocytic routes reveals macropinocytosis as an alternative entry pathway. PLoS Pathog. 7, e1001329. doi:10.1371/journal.ppat.1001329

Diebold, S. S., Kaisho, T., Hemmi, H., Akira, S., and Reis E Sousa, C. (2004). Innate antiviral responses by means of TLR7-mediated recognition of tributes to hyperinduction of proin-

in antigen presenting cells or if the different binding by those HAs induces distinct signaling cascades in those cells.

\section{ACKNOWLEDGMENTS}

We thank Sarah Pagni for kindly reviewing the manuscript. Data discussed in this review from the Fernandez-Sesma group was funded by the National Institutes of Health (NIH) and the NIH Center of Excellence for Influenza Research and Surveillance (CEIRS; grant HHSN266200700010C to Ana Fernandez-Sesma).

single-stranded RNA. Science 303, 1529-1531.

Eierhoff, T., Hrincius, E. R., Rescher, U., Ludwig, S., and Ehrhardt, C. (2010). The epidermal growth factor receptor (EGFR) promotes uptake of influenza A viruses (IAV) into host cells. PLoS Pathog. 6, e1001099. doi:10.1371/journal.ppat.1001099

Enserink, M. (2007). Virology from two mutations, an important clue about the Spanish flu. Science 315, 582.

Garcia-Sastre, A. (2011). Induction and evasion of type I interferon responses by influenza viruses. Virus Res. 162, 12-18.

Geijtenbeek, T. B., and Gringhuis, S. I. (2009). Signalling through C-type lectin receptors: shaping immune responses. Nat. Rev. Immunol. 9, 465-479.

Gonzalez, S. F., Lukacs-Kornek, V., Kuligowski, M. P., Pitcher, L. A., Degn, S. E., Kim, Y. A., Cloninger, M. J., Martinez-Pomares, L., Gordon, S., Turley, S. J., and Carroll, M. C. (2010). Capture of influenza by medullary dendritic cells via SIGN$\mathrm{R} 1$ is essential for humoral immunity in draining lymph nodes. Nat. Immunol. 11, 427-434.

Ichinohe, T., Lee, H. K., Ogura, Y., Flavell, R., and Iwasaki, A. (2009). Inflammasome recognition of influenza virus is essential for adaptive immune responses. J. Exp. Med. 206, 79-87.

Kang, Y. S., Yamazaki, S., Iyoda, T., Pack, M., Bruening, S. A., Kim, J. Y., Takahara, K., Inaba, K., Steinman, R. M., and Park, C. G. (2003). SIGNR1, a novel C-type lectin expressed by marginal zone macrophages in spleen, mediates uptake of the polysaccharide dextran. Int. Immunol. 15, 177-186.

Kawai, T., Kase, T., Suzuki, Y., Eda, S., Sakamoto, T., Ohtani, K., and Wakamiya, N. (2007). Antiinfluenza A virus activities of mannan-binding lectins and bovine conglutinin. J. Vet. Med. Sci. 69, 221-224.

Lakadamyali, M., Rust, M. J., and Zhuang, X. (2004). Endocytosis of influenza viruses. Microbes Infect. 6, 929-936.
Lakadamyali, M., Rust, M. J., and Zhuang, X. (2006). Ligands for clathrin-mediated endocytosis are differentially sorted into distinct populations of early endosomes. Cell 124, 997-1009.

Lee, S. M., Cheung, C. Y., Nicholls, J. M., Hui, K. P., Leung, C. Y., Uiprasertkul, M., Tipoe, G. L., Lau, Y. L., Poon, L. L., Ip, N. Y., Guan, Y., and Peiris, J. S. (2008). Hyperinduction of cyclooxygenase-2-mediated proinflammatory cascade: a mechanism for the pathogenesis of avian influenza H5N1 infection. J. Infect. Dis. 198, 525-535.

Lee, S. M., Gardy, J. L., Cheung, C. Y., Cheung, T. K., Hui, K. P., Ip, N. Y., Guan, Y., Hancock, R. E., and Peiris, J. S. (2009). Systems-level comparison of host-responses elicited by avian $\mathrm{H} 5 \mathrm{~N} 1$ and seasonal $\mathrm{H} 1 \mathrm{~N} 1$ influenza viruses in primary human macrophages. PLoS ONE 4, e8072. doi:10.1371/journal.pone.0008072

Liu, W. C., Lin, S. C., Yu, Y. L., Chu, C. L., and Wu, S. C. (2010). Dendritic cell activation by recombinant hemagglutinin proteins of $\mathrm{H} 1 \mathrm{~N} 1$ and $\mathrm{H} 5 \mathrm{~N} 1$ influenza A viruses. $J$. Virol. 84, 12011-12017.

Londrigan, S. L., Turville, S. G., Tate, M. D., Deng, Y. M., Brooks, A. G., and Reading, P. C. (2011). N-linked glycosylation facilitates sialic acidindependent attachment and entry of influenza A viruses into cells expressing DC-SIGN or L-SIGN. J. Virol. 85, 2990-3000.

Lyszkiewicz, M., Zietara, N., Rohde, M., Gekara, N. O., Jablonska, J., Dittmar, K. E., and Weiss, S. (2011). SIGN$\mathrm{R} 1+\mathrm{MHC} \mathrm{II}+$ cells of the splenic marginal zone - a novel type of resident dendritic cells. J. Leukoc. Biol. 89, 607-615.

Maines, T. R., Chen, L. M., Matsuoka, Y., Chen, H., Rowe, T., Ortin, J., Falcon, A., Nguyen, T. H., Mai Le, Q., Sedyaningsih, E. R., Harun, S., Tumpey, T. M., Donis, R. O., Cox, N. J., Subbarao, K., and Katz, J. M. (2006). Lack of transmission of $\mathrm{H} 5 \mathrm{~N} 1$ avian-human reassortant influenza viruses in a ferret model. Proc. Natl. Acad. Sci. U.S.A. 103, 12121-12126. 
Maines, T. R., Szretter, K. J., Perrone, L., Belser, J. A., Bright, R. A., Zeng, H., Tumpey, T. M., and Katz, J. M. (2008). Pathogenesis of emerging avian influenza viruses in mammals and the host innate immune response. Immunol. Rev. 225, 68-84.

Matsuoka, Y., Lamirande, E. W., and Subbarao, K. (2009). The ferret model for influenza. Curr. Protoc. Microbiol. Chapter 15, Unit 15G 12.

Miller, J. L., and Anders, E. M. (2003). Virus-cell interactions in the induction of type 1 interferon by influenza virus in mouse spleen cells. J. Gen. Virol. 84, 193-202.

Mubareka, S., and Palese, P. (2011). "Influenza virus: the biology of a changing virus," in Influenza Vaccines for the Future, eds G. D. Giudice and R. Rappuoli (Basel: Springer), 3-26.

Nakanaga, T., Nadel, J. A., Ueki, I. F., Koff, J. L., and Shao, M. X. (2007). Regulation of interleukin- 8 via an airway epithelial signaling cascade. Am. J. Physiol. Lung Cell Mol. Physiol. 292, L1289-L1296.

Neumann, G., and Kawaoka, Y. (2006). Host range restriction and pathogenicity in the context of influenza pandemic. Emerging Infect. Dis. 12, 881-886.

Nicholls, J. M., Chan, M. C., Chan, W. Y., Wong, H. K., Cheung, C. Y., Kwong, D. L., Wong, M. P., Chui, W. H., Poon, L. L., Tsao, S. W., Guan, Y., and Peiris, J. S. (2007). Tropism of avian influenza A (H5N1) in the upper and lower respiratory tract. Nat. Med. 13, 147-149.

Palese, P., and Shaw, M. L. (2007). "Orthomyxoviridae: the viruses and their replication," in Fields Virol$o g y$, 5th Edn, eds D. M. Knipe and P. M. Howley (Philadelphia, PA: Lippincott Williams \& Wilkins), 1647-1689.

Peiris, J. S., Yu, W. C., Leung, C. W., Cheung, C. Y., Ng, W. F., Nicholls, J. M., Ng, T. K., Chan, K. H., Lai, S. T., Lim, W. L., Yuen, K. Y., and Guan, Y. (2004). Re-emergence of fatal human influenza A subtype H5N1 disease. Lancet 363, 617-619.

Ramos, I., Bernal-Rubio, D., Durham, N., Belicha-Villanueva, A., Lowen,
A. C., Steel, J., and FernandezSesma, A. (2011). Effects of receptor binding specificity of avian influenza virus on the human innate immune response. J. Virol. 85, 4421-4431.

Reading, P. C., Miller, J. L., and Anders, E. M. (2000). Involvement of the mannose receptor in infection of macrophages by influenza virus. $J$. Virol. 74, 5190-5197.

Rogers, G. N., and Paulson, J. C. (1983). Receptor determinants of human and animal influenza virus isolates: differences in receptor specificity of the $\mathrm{H} 3$ hemagglutinin based on species of origin. Virology 127, 361-373.

Seeds, R. E., Mukhopadhyay, S., Jones, I. M., Gordon, S., and Miller, J. L. (2011). The role of myeloid receptors on murine plasmacytoid dendritic cells in induction of type I interferon. Int. Immunopharmacol. 11, 794-801.

Shinya, K., Ebina, M., Yamada, S., Ono, M., Kasai, N., and Kawaoka, Y. (2006). Avian flu: influenza virus receptors in the human airway. Nature 440, 435-436.

Sirinonthanawech, N., Uiprasertkul, M., Suptawiwat, O., and Auewarakul, P. (2011). Viral load of the highly pathogenic avian influenza $\mathrm{H} 5 \mathrm{~N} 1$ virus in infected human tissues. J. Med. Virol. 83, 1418-1423.

Stamatos, N. M., Carubelli, I., Van De Vlekkert, D., Bonten, E. J., Papini, N., Feng, C., Venerando, B., D’Azzo, A., Cross, A. S., Wang, L. X., and Gomatos, P. J. (2010). LPS-induced cytokine production in human dendritic cells is regulated by sialidase activity. J. Leukoc. Biol. 88, 1227-1239.

Stevens, J., Blixt, O., Glaser, L., Taubenberger, J. K., Palese, P., Paulson, J. C., and Wilson, I. A. (2006a). Glycan microarray analysis of the hemagglutinins from modern and pandemic influenza viruses reveals different receptor specificities. J. Mol. Biol. 355, 1143-1155.

Stevens, J., Blixt, O., Paulson, J. C., and Wilson, I. A. (2006b). Glycan microarray technologies: tools to survey host specificity of influenza viruses. Nat. Rev. Microbiol. 4 857-864.

Subauste, M. C., and Proud, D. (2001). Effects of tumor necrosis factoralpha, epidermal growth factor and transforming growth factor-alpha on interleukin-8 production by, and human rhinovirus replication in, bronchial epithelial cells. Int Immunopharmacol. 1, 1229-1234.

Tumpey, T. M., Maines, T. R., Van Hoeven, N., Glaser, L., Solorzano, A. Pappas, C., Cox, N. J., Swayne, D. E. Palese, P., Katz, J. M., and GarciaSastre, A. (2007). A two-amino acid change in the hemagglutinin of the 1918 influenza virus abolishes transmission. Science 315, 655-659.

Upham, J. P., Pickett, D., Irimura, T., Anders, E. M., and Reading, P. C. (2010). Macrophage receptors for influenza A virus: role of the macrophage galactose-type lectin and mannose receptor in viral entry. J. Virol. 84, 3730-3737.

Van Riel, D., Munster, V. J., De Wit, E., Rimmelzwaan, G. F., Fouchier, R. A., Osterhaus, A. D., and Kuiken, T. (2006). H5N1 virus attachment to lower respiratory tract. Science $312,399$.

Videira, P. A., Amado, I. F., Crespo, H. J., Alguero, M. C., Dall'Olio, F., Cabral, M. G., and Trindade, H. (2008). Surface alpha 2-3- and alpha 2-6sialylation of human monocytes and derived dendritic cells and its influence on endocytosis. Glycoconj. J. 25, 259-268.

Wang, S. F., Huang, J. C., Lee, Y M., Liu, S. J., Chan, Y. J., Chau, Y. P., Chong, P., and Chen, Y. M. (2008). DC-SIGN mediates avian $\mathrm{H} 5 \mathrm{~N} 1$ influenza virus infection in cis and in trans. Biochem. Biophys. Res. Commun. 373, 561-566.

Watanabe, T., Shinya, K., Watanabe, S. Imai, M., Hatta, M., Li, C., Wolter, B. F., Neumann, G., Hanson, A., Ozawa, M., Yamada, S., Imai, H., Sakabe, S., Takano, R., Iwatsuki-Horimoto, K., Kiso, M., Ito, M., Fukuyama, S., Kawakami, E., Gorai, T., Simmons, H. A., Schenkman, D., Brunner, K. Capuano, S. V. III, Weinfurter, J. T. Nishio, W., Maniwa, Y., Igarashi, T., Makino, A., Travanty, E. A., Wang,
J., Kilander, A., Dudman, S. G., Suresh, M., Mason, R. J., Hungnes, O., Friedrich, T. C., and Kawaoka, Y. (2011). Avian-type receptor-binding ability can increase influenza virus pathogenicity in macaques. J. Virol. 13195-13203.

Weis, W., Brown, J. H., Cusack, S., Paulson, J. C., Skehel, J. J., and Wiley, D. C. (1988). Structure of the influenza virus haemagglutinin complexed with its receptor, sialic acid. Nature 333, 426-431.

WHO. (2011). Cumulative Number of Confirmed Human Cases of Avian Influenza $A /(H 5 N 1)$ Reported to WHO. Available at: http://www. who.int/influenza/human_animal_ interface/H5N1_cumulative_table_ archives/en/index.html

Wise, H. M., Foeglein, A., Sun, J., Dalton, R. M., Patel, S., Howard, W., Anderson, E. C., Barclay, W. S., and Digard, P. (2009). A complicated message: identification of a novel PB1-related protein translated from influenza $A$ virus segment 2 mRNA. J. Virol. 83, 8021-8031.

Conflict of Interest Statement: The authors declare that the research was conducted in the absence of any commercial or financial relationships that could be construed as a potential conflict of interest.

Received: 19 January 2012; accepted: 12 March 2012; published online: 28 March 2012.

Citation: Ramos I and Fernandez-Sesma A (2012) Cell receptors for influenza A viruses and the innate immune response. Front. Microbio. 3:117. doi: 10.3389/fmicb.2012.00117

This article was submitted to Frontiers in Virology, a specialty of Frontiers in Microbiology.

Copyright (C) 2012 Ramos and Fernandez-Sesma. This is an openaccess article distributed under the terms of the Creative Commons Attribution Non Commercial License, which permits non-commercial use, distribution, and reproduction in other forums, provided the original authors and source are credited. 